\title{
Comparing Yields and Nematode Control of Soybean Varieties with Different Sources of SCN Resistance in Strip Trials
}

\author{
Gregory Tylka, professor \\ Chris Marett, assistant scientist \\ Department of Plant Pathology
}

\section{Introduction}

The primary method of managing yield loss due to the soybean cyst nematode (SCN) is through the use of resistant soybean varieties. Most SCN-resistant varieties available in Iowa have the PI 88788 source of SCN resistance. There are concerns that over time, $\mathrm{SCN}$ will be able to overcome the PI 88788 resistance.

Small plots (two or four rows wide and up to $20 \mathrm{ft}$ long) often are used to evaluate yields and nematode control of SCN-resistant soybean varieties. Yield results are more variable in small plots than in larger strip plots, but data from soil samples in small plots more accurately represent SCN population densities from the areas in which yield data are being collected.

In this experiment, varieties with SCNresistance from PI 88788, Peking, and PI $437654\left(\right.$ CystX $\left.^{\circledR}\right)$ were compared. We attempted to capture the strengths of strip plots and small plots by growing the varieties in strips and taking multiple soil samples from each strip.

\section{Materials and Methods}

Four replications of seven soybean varieties were planted in randomly ordered strips on May 24, 2008. Each strip had six rows, $200 \mathrm{ft}$ long, spaced 30 in. apart. Five of the varieties were resistant to SCN and two were susceptible. Two varieties had SCN resistance from PI 88788, two varieties had Peking SCN resistance, and one variety had PI 437654 $\left(\right.$ CystX $\left.^{\circledR}\right)$ SCN resistance. Each 200-ft-long strip was sampled in 25-ft increments; eight different soil samples were collected per strip. Each soil sample consisted of 10 soil cores from the center two rows of the $25-\mathrm{ft}$ increment. Spring soil samples were taken on May 28, the plots were harvested on October 10, and soil samples were collected a second time on October 21, 2008. A greenhouse HG type test was performed on the SCN population obtained in the spring soil samples.

\section{Results and Discussion}

In the tables, nematode reproduction is indicated by a reproductive factor (RF) value, which is calculated by dividing the number of SCN eggs in a plot in the fall by the number that were present in the spring. RF values $>1.0$ indicate $\mathrm{SCN}$ numbers increased during the growing season; RF values $<1.0$ indicate that SCN numbers declined. Initially, there were 2,069 SCN eggs/100 cc soil in the field overall, and the HG type of the SCN population was 2.5 .7 , with 10 percent reproduction on PI 88788.

In this experiment, all of the varieties with Peking and $\mathrm{CystX}^{\circledR}$ resistance, and one of the varieties with PI 88788 resistance, significantly reduced SCN population densities compared with the susceptible varieties (Table 1). One of the Peking varieties yielded more than the susceptible varieties, but the $\mathrm{Cyst}^{\circledR}$ variety yielded significantly less than the susceptible varieties (Table 1). When results were combined by source of $\mathrm{SCN}$ resistance, all three sources either prevented increases in $\mathrm{SCN}$ population densities or actually reduced SCN numbers 
during the season (Table 2). Only the varieties with Peking SCN resistance had yields greater than the susceptible varieties. The yield of varieties with PI $88788 \mathrm{SCN}$ resistance was numerically greater than the susceptible, but the difference was not statistically significant. The Cyst ${ }^{\circledR}$ variety reduced SCN numbers, but it also was the lowest-yielding variety in the experiment. The SCN RF value of varieties with PI $88788 \mathrm{SCN}$ resistance was numerically greater than the RF values of the other sources of SCN resistance, which makes sense because the HG type test results indicated that the SCN population in the field had 10 percent reproduction on PI 88788.

These results illustrate that SCN-resistant soybean varieties may need to be selected based on the conditions in each field. Growers seeking to reduce $\mathrm{SCN}$ numbers may do best by growing varieties with Peking or Cyst $\mathrm{X}^{\circledR}$ SCN resistance. The results also show that varieties with PI 88788 resistance can yield well even in fields with SCN populations with 10 percent reproduction on PI 88788 (like HG type 2.5.7).

\section{Acknowledgements}

We thank Dave Rueber and the staff of the ISU Northern Research and Demonstration Farm for their help with this study. This work was funded by the soybean checkoff through a grant from the North Central Soybean Research Program.

Table 1. Soybean yield and SCN reproduction by variety (Kanawha 2008 ).

\begin{tabular}{lcclll}
\hline Soybean variety & Source of SCN resistance & Yield (bu/acre) & SCN RF $^{1}$ \\
\hline Latham E2658R & PI 88788 & 39.2 & $\mathrm{a} \mathrm{b}$ & 1.0 & $\mathrm{c}$ \\
Latham L2620RX & Cyst X & 34.5 & $\mathrm{c}$ & 0.5 & $\mathrm{c}$ \\
Latham L2646R & None & 37.2 & $\mathrm{~b} \mathrm{c}$ & 2.5 & $\mathrm{a} \mathrm{b}$ \\
Pioneer 92M11 & Peking & 40.3 & $\mathrm{a}$ & 0.7 & $\mathrm{c}$ \\
Pioneer 92M53 & Peking & 39.2 & $\mathrm{a} \mathrm{b}$ & 0.7 & $\mathrm{c}$ \\
Pioneer 92M54 & PI 88788 & 39.2 & $\mathrm{a} \mathrm{b}$ & 1.5 & $\mathrm{~b} \mathrm{c}$ \\
Pioneer 92M91 & None & 36.7 & $\mathrm{~b} \mathrm{c}$ & 3.3 & $\mathrm{a}$ \\
\hline
\end{tabular}

Numbers in columns followed by the same letter are not statistically different $(\mathrm{P}=0.10)$.

${ }^{1} \mathrm{RF}$, fall $\mathrm{SCN}$ population $\div$ spring $\mathrm{SCN}$ population.

Table 2. Soybean yield and SCN reproduction by resistance source (Kanawha 2008).

\begin{tabular}{lllll}
\hline Source & \multicolumn{2}{c}{ Yield } & \multicolumn{2}{c}{$\mathrm{RF}^{1}$} \\
\hline None & 36.9 & $\mathrm{~b} \mathrm{c}$ & 2.9 & $\mathrm{a}$ \\
PI 88788 & 39.2 & $\mathrm{a} \mathrm{b}$ & 1.2 & $\mathrm{~b}$ \\
Peking & 39.8 & $\mathrm{a}$ & 0.7 & $\mathrm{~b}$ \\
Cyst X & 34.5 & $\mathrm{c}$ & 0.5 & $\mathrm{~b}$ \\
\hline
\end{tabular}

Numbers in columns followed by the same letter are not statistically different $(\mathrm{P}=0.10)$.

${ }^{1} \mathrm{RF}$, fall $\mathrm{SCN}$ population $\div$ spring $\mathrm{SCN}$ population. 